\title{
A experiência da esquistossomose e os desafios da mobilização comunitária
}

\author{
Schistosomiasis and the challenge \\ of community participation
}

Paulo César Alves 1

Iara Maria Souza 1

Milton Araújo Moura 1

Litza Andrade Cunha 1

\footnotetext{
1 Núcleo de Estudos em Ciências Sociais e Saúde, Faculdade de Filosofia e Ciências Humanas, Universidade Federal da Bahia. Estrada de São Lázaro 197, Federação, Salvador, BA 40210-730, Brasil.
}

\begin{abstract}
Using a semiotic and hermeneutical approach, the present paper discusses various theoretical elements in the analysis of popular views of schistosomiasis. Based on field work conducted in the State of Bahia, the authors identify two main processes in the construction of meaning related to schistosomiasis and show that depending on the social context of experience the disease may have a primary or secondary meaning for the populations affected by it. The first level of meaning refers to bodily experiences and is shared intersubjectively, whereas the second type is built on the discourse of health professionals. In the latter case, the popular view of the illness is directly linked to discourses and actions previously established by health programs designed for the control of the disease.
\end{abstract}

Key words Shistosomiasis; Consumer Participation; Community Participation; Sociology, Medical

Resumo Utilizando-se da abordagem semiótica e hermenêutica, o presente artigo discute algumas premissas relacionadas a análise da concepção popular de esquistossomose. Valendo-se de um trabalho de campo realizado no Estado da Bahia, são identificadas duas situações em que os atores sociais, em contextos específicos, constroem as significações dessa endemia: a significação de "primeiro grau" e de "segundo grau". O primeiro tipo de significação refere-se a experiências sensíveis, corporais e é intersubjetivamente compartilhada, enquanto que o segundo tipo é construído com base em significados formulados pelos agentes de saúde. Nesse último caso, a construção popular da doença está diretamente vinculada aos discursos e ações previamente estabelecidos por programas específicos de controle e combate da endemia.

Palavras-chave Esquistossomose; Participação Comunitária; Sociologia Médica 
“... é uma ciência difícil essa xistosoma"

\section{Introdução}

É comum, principalmente nos estudos sócioantropológicos da saúde, se estabelecer uma diferença entre a concepção biomédica e popular da doença. A primeira, objeto de investigação do setor médico profissional, está baseada na pressuposição de que a doença é uma disfunção ou alteração de caráter orgânico ou psíquico. Como tal, constitui-se em um fato de ordem natural, sujeito às suas próprias “leis” e não depende necessariamente da forma peculiar de como é expressa pelos indivíduos. Processos ou estados patológicos podem estar presentes no nosso corpo sem que tenhamos consciência deles. A concepção popular da doença, por outro lado, não pode ser definida em termos que sejam desvinculados das condições sócio-culturais e, portanto, das situações estabelecidas por tempo e lugar determinados. Ela só se evidencia através de processos interativos entre os atores sociais, no conjunto de práticas e instituições organizadas e expressas por grupos específicos. Dessa forma, devido à diversidade dos contextos e situações sócio-culturais, podemos encontrar vários modelos interpretativos para o fenômeno da doença.

Para as ciências sociais, a enfermidade está circunscrita a quadros explicativos que diferem do modelo biomédico, embora sofram sua influência (Kleinman, 1980). Um dos pressupostos básicos dessas ciências é de que o conjunto de idéias e "crenças" relativas à doença é resultado de determinadas estruturas cognitivas e relações sociais que configuram as experiências vivenciadas pelos indivíduos. Tal pressuposto pode ser evidenciado nos estudos sobre a "experiência da doença". Esses estudos caracterizam-se por tentar compreender como os indivíduos, em situações sociais específicas, adquirem seus conhecimentos "médicos" e vivenciam determinadas experiências por eles consideradas como "enfermidades". Assim, trata-se de trabalhos que objetivam investigar, entre outros aspectos, os diferentes meios pelos quais os indivíduos dão significados às suas vivências de aflição. Partem do princípio de que é com a compreensão de ações humanas concretas que podemos explicar como os indivíduos compartilham e legitimam suas idéias e atitudes com respeito a determinadas doenças.

Nos estudos sobre as experiências da doença há de se considerar algumas premissas que nos parecem essenciais. Uma delas diz respei- to ao fato de que o cientista social deve levar em devida consideração a "atitude natural" na qual todo indivíduo põe a si mesmo como um ser que está sempre vivenciando algo e se "encontrando" com coisas e pessoas (Schutz, 1975: 72-76). Esses encontros ou experiências têm uma pretensão de evidência absoluta. O conhecimento e a experiência que os indivíduos têm do mundo dependem da forma como eles "encontram" os outros seres, coisas e pessoas, que estão no seu “entorno” (Husserl, 1994:56). São desses encontros ou vivências que os indivíduos desenvolvem um "estoque de conhecimento à mão" necessário para que possam lidar com os complexos processos interativos existentes no seu mundo social.

A premissa acima esboçada é fundamental para que possamos compreender como os indivíduos vivenciam a doença. Dentro dessa perspectiva, os cientistas sociais tendem a interpretar a consciência de se estar doente como resultado de experiências corporais (ou psíquicas), isso é, como resultado de "informações” produzidas pelo corpo. Assim, é necessário que o corpo revele que "algo não vai bem", para que se possa falar em doença. Contudo, subordinar a idéia de experiência a sensações de mal estar é limitar o conceito de experiência. É importante observar que ao se enfatizar o primado da experiência, o que deve ser tomado como evidente para os indivíduos não é apenas tais sensações, mas o que é "encontrado" e posto como existente por eles. No nosso mundo também nos deparamos com idéias, com concepções que são emitidas por outros indivíduos. Assim, o substrato da experiência, o que é nela encontrado, pode se constituir em um conjunto de significados e atitudes concretamente estabelecidos por outras pessoas. Dessa forma, os juízos, os discursos e ações relacionados ao fenômeno saúde/doença, elaborados por pessoas socialmente legitimadas, podem se constituir em algo real, em substratos concretos por meio dos quais construímos os nossos significados da doença.

É importante também lembrar que se para o indivíduo a doença se inicia com uma experiência, isso não significa dizer que toda ela derive dessa experiência. O mundo "empírico", o conteúdo da experiência, é sempre percebido mediante um dado sistema de significações que são construídas e partilhadas por indivíduos ou grupos sociais. Mesmo as sensações como dor de cabeça, fraqueza, vômitos, febre, tomados como fatos isolados, não revelam em si mesmos uma determinada enfermidade. A doença é conceitualizada quando essas "matérias brutas” das impressões sensíveis são orga- 
nizadas por processos de significações. O mesmo ocorre quando lidamos com experiências assentadas em ações e processos discursivos desenvolvidos por determinados agentes sociais. Nesses casos, o significado da doença é construção sobre um outro significado

Tomando em consideração as premissas acima esboçadas, o objetivo do presente estudo é estabelecer algumas considerações que possam elucidar os processos pelos quais os indivíduos constroem significados sobre uma determinada enfermidade: a esquistossomose. Mais especificamente, procuramos examinar algumas situações por intermédio das quais as pessoas desenvolvem um conhecimento específico sobre essa endemia. Tal investigação nos parece importante pois com ela esperamos lançar alguma luz sobre os limites e potencialidades das práticas relativas à mobilização comunitária subjacente a determinadas políticas sanitárias. Nesse aspecto, objetivamos contribuir para a discussão de como modelos interpretativos apresentados pelas campanhas de controle e combate da esquistossomose permitem compreender as formas ou processos pelos quais os indivíduos dão significado à essa doença.

Os resultados apresentados no presente artigo são provenientes de uma pesquisa realizada no Estado da Bahia, entre julho e dezembro de 1996. Essa pesquisa, financiada pelo Banco Mundial e pelo Ministério da Saúde (Fundação Nacional de Saúde - FNS) e sob a coordenação nacional do Dr. Victor Valla, foi desenvolvida por uma equipe de pesquisadores do Núcleo de Estudos em Ciências Sociais, Ambiente e Saúde (ECSAS) da Faculdade de Filosofia e Ciências Humanas da Universidade Federal da Bahia, sob a responsabilidade do Dr. Paulo César Alves. A pesquisa procurou investigar os significados de participação social e mobilização comunitária subjacente aos projetos de controle e combate à esquistossomose desenvolvidos, na Bahia, pela Fundação Nacional de Saúde através do programa PCDEN (Programa de Controle de Doenças Endêmicas do Nordeste). Uma especial ênfase foi dada às ações realizadas pelo componente IEC (Informação, Educação e Comunicação) do PCDEN. Com vista a tal objetivo, dois dos noves distritos administrativos da FNS-BA foram selecionados: Pernambués e Jequié. Nesses distritos foram escolhidas nove localidades. Com exceção de duas, as demais localidades são áreas consideradas pela FNS como endêmicas, isto é, com prevalência acima de $20 \%$ de pessoas com exame positivo.

\section{O "encontrado" nas experiências da esquistossomose}

Ao procurar investigar o processo de construção de significado que os indivíduos atribuem à esquistossomose, torna-se necessário estabelecer inicialmente os parâmetros pelos quais essa doença é concebida pelas instituições oficiais de saúde.

Em primeiro lugar, deve-se observar que a esquistossomose - conhecida popularmente como xistossomose, xistosa, "doença do caramujo” ou "barriga d'água” - é pensada pelos órgãos públicos como uma doença de veiculação hídrica, diretamente ligada às condições de saneamento e à maneira de viver das populações situadas em áreas endêmicas. Produzida por trematódeos, organismos (metazoários) endoparasitos, a transmissão da Schistosoma mansoni depende do inter-relacionamento entre o ecossistema, as pessoas e suas condições sociais. O contato humano com as coleções de água doce e de superfície, adequada à vida dos moluscos hospedeiros intermediários (o caramujo), a presença de pessoas parasitadas, a densidade da população de caramujos, os hábitos de poluição fecal do ambiente e condições econômicas (como a disponibilidade de água domiciliar e condições sanitárias), são fatores que determinam, em diferentes níveis, as medidas dessa infecção.

A maior taxa de prevalência e as manifestações mais graves ocorrem em crianças e jovens com 5 a 15 anos de idade (Rey, 1991). Essa infecção, contudo, não é usualmente acompanhada de sintomas importantes. Quando se manifestam, os sintomas são geralmente vagos: perda de apetite, emagrecimento e pequeno desconforto abdominal. Assim, o indivíduo infectado não percebe a doença de que é portador, sendo capaz de executar as suas tarefas cotidianas. Esse fato explica porque pacientes com manifestações subclínicas não recorrem comumente aos serviços médicos. Somente em quadros clínicos mais sérios é que o indivíduo sente dores abdominais, diarréia, febre, cefaléia, prostração, estado de depressão, anorexia e outros sintomas. São nesses casos, principalmente quando as manifestações clínicas da doença são predominantemente intestinais (quadros hepatoesplênicos bem constituídos), que o indivíduo procura o médico. A morbidade crônica, quando ocorre, acontece geralmente após muitos anos da infecção. Menos de $10 \%$ dos indivíduos infestados desenvolvem lesões esquistossomóticas (Rey, 1991; Bina \& Prata, 1984). Assim, é importante ressaltar que a infecção humana provocada pela $S$. mansoni, por 
não se apresentar habitualmente de forma aguda ou toxêmica, é usualmente assintomática. Esse fato é importante para compreendermos como popularmente é constituída a idéia de esquistossomose.

A percepção dessa infecção, enquanto assintomática, não é necessariamente proveniente de experiências produzidas por sensações corporais. Assim, para o cientista social, é fundamental observar o que é imediatamente dado à experiência da esquistossomose é um conjunto de ações e formas de mediação simbólico-normativas desenvolvidas por "outros" indivíduos ou grupos sociais. Nesse aspecto, o primariamente encontrado nessa experiência são valores, representações e práticas produzidos, em situações histórico-sociais concretas, por discursos e modos de agir de determinados agentes e/ou profissionais da saúde. É por meio das suas atividades e das narrativas que desenvolvem para interpretar a doença que estes profissionais estabelecem, por assim dizer, um fundo da atividade de produção expressiva que se encontra na base da experiência popular da esquistossomose. Nessa perspectiva, tais agentes tendem a estabelecer orientações estratégicas e normativas, pelas quais objetivam a doença, o seu diagnóstico e o seu tratamento. Assim, torna-se necessário explicitar o processo pelo qual esses agentes constroem significados no controle e combate da esquistossomose.

Um dos primeiros aspectos a ser observado no controle e combate da esquistossomose é a de que essa doença tem se constituído em um grande desafio nas orientações estratégicas da saúde pública (Iyda, 1994). Trata-se, como é de conhecimento geral, de uma doença que apresenta altas taxas de prevalência e, devido a processos de migração, a presença de pacientes portadores da parasitose é observada na maioria dos países. Calcula-se que cerca de $200 \mathrm{mi}$ lhões de pessoas na América, África e Ásia estão infectadas por Schistosoma. Essa doença é endêmica em setenta e quatro países e territórios. No Brasil, uma espécie desse agente etiológico (S. mansoni) constitui sério problema de saúde pública, a sua infecção é responsável pela contaminação de aproximadamente seis milhões de indivíduos. A área endêmica mais importante do país está localizada no Nordeste, em uma faixa de terra que abrange as regiões orientais do Rio Grande do Norte até a Bahia, parte de Minas Gerais e a Zona Serrana do Espírito Santo. Contudo, devido principalmente à mobilidade populacional nessa área, a presença de pacientes portadores da parasitose é observada em muitos outros estados brasileiros (Barreto, 1984).
No Brasil, as primeiras ações para o controle e combate da esquistossomose foram implementadas na década de 50. Decorrentes de experiências acumuladas por sucessivas concepções sobre o tratamento da doença, foi criado no final da década de 80, com os recursos em grande parte provenientes do Banco Mundial, o PCDEN (Programa de Controle de Doenças Endêmicas do Nordeste). Esse programa, em certos aspectos, pode ser considerado como um marco no contexto institucional da Sucam (e, posteriormente, da FNS), na medida em que concretizou algumas mudanças estratégicas para as ações de controle de endemia, que já começavam a ganhar visibilidade desde meados da década. É importante observar, contudo, que as propostas pedagógicas e educacionais do PCDEN continuam a conviver, embora, às vezes, de forma problemática, com as práticas anteriormente existentes de controle e combate direto da esquistossomose. Na realidade, esse Programa propõe agregar uma "nova” concepção de trabalho educativo às práticas anteriormente já existentes, como os inquéritos parasitológicos, o uso de medicamentos esquistossomicidas, ações malacológicas e saneamento básico (construção de esgotos e instalações sanitárias). Uma diferença que nos parece fundamental é que anterior ao PCDEN, as propostas educativas objetivavam, na prática, apenas conseguir de uma determinada população a sua cooperação na execução de tais medidas profiláticas.

Nas entrevistas realizadas com diversos agentes de saúde, o componente educativo no controle e combate da esquistossomose parece assumir um papel preponderante, o que não significa dizer que os técnicos da Sucam-FNS compartilhem de uma mesma idéia sobre qual medida de ação pedagógica deva ser considerada como a mais apropriada para a doença.

Uma concepção mais "tradicional" no controle e combate da esquistossomose pode ser observada no seguinte relato de um inspetor de endemia: "o próprio guarda em campo leva um jogo de kit, distribuindo os coletores e recolhendo o material para análise. É a figura do guarda montador. Os servidores saem para distribuir os coletores e recolher o material e trazem para a linha de montagem (...) Inicialmente para cada inquérito, fazíamos o inquérito concorrente. Examinávamos a mesma população de 7-14 anos para fazer o comparativo da eliminação da carga parasitária (...) Quando passamos a conhecer a situação de outros municípios (...) começamos a fazer uma cobertura censitária, visitando toda a população das áreas onde a prevalência estava acima de 5\% 
(...) Concomitante ao inquérito, fazemos o levantamento malacológico. Consiste em levantar todas as coleções hídricas existentes no município e assinalar no mapa, amarrando-as a um boletim. Feita a identificação, vamos fazer a pesquisa para verificar se há a presença do caramujo. Havendo a presença do caramujo, vamos considerar como foco de esquistossomose, a princípio. Os caramujos deveriam ser então examinados para ver se estão ou não infectados. A presença do caramujo é um indício. É a própria população humana que vem contaminar o caramujo".

Esse mesmo inspetor, contudo, ao relatar as dificuldades encontradas, observa: "Mas a situação é difícil. A esquistossomose é uma doença difícil de combater, pelo fato de que as pessoas que residem nas áreas endêmicas não apresentam problemas de saúde. As pessoas não sentem os efeitos. Quando os efeitos não são levados à transparência, torna-se difícil (...) Algumas pessoas duvidam do diagnóstico dado (...) elas questionam. Sucessivas visitas às casas levam as pessoas ao desinteresse, como se estivéssemos adulando. Existem momentos do trabalho em que foi necessário 10, 12, até 15 visitas para conseguir coletar o material (...) É difícil quebrar essa resistência. Fazemos a divulgação através de rádio local, alto-falante, faixas Esperamos com isso que a população fique mais sensibilizada com o nosso trabalho".

As medidas profiláticas isoladas de programas educativos voltados para o controle e combate de uma endemia específica têm sido objeto de discussão pelo menos desde a década de 80. Em 1979, por exemplo, um relatório produzido pela Divisão Nacional de Educação em Saúde sobre a atuação do Pece (Programa Especial de Controle da Esquistossomose) em duas comunidades do Nordeste, já insistia na necessidade de que as mudanças pretendidas nas ações educativas se fizessem por meio de um processo contínuo em que fossem utilizados os próprios recursos humanos da comunidade (Prata et al., 1981). No Primeiro Encontro dos Educadores da Sucam (abril de 1983) discutiu-se amplamente a necessidade de se criar novas estratégias educativas para o controle das endemias. A metodologia participativa foi considerada como a estratégia básica para operacionalizar os objetivos da educação em saúde. Essa metodologia, conforme o Relatório das Atividades do Sesan/Superintendência de 1984 (MS, 1984), deveria ser utilizada para garantir a participação das comunidades representadas por indivíduos, grupos e instituições, como medida de aumento da eficácia dos programas. Influenciada pela crescente discussão sobre ação comunitária e mobilização social (Amman, 1980; Pinto, 1981; Prates, 1984, entre outros), a Superintendência de Campanhas de Saúde Pública (Sucam) começou então a reformular o significado de educação em saúde.

No PCDEN, os objetivos gerais dessa nova "metodologia educativa" podem ser observados no documento Diretrizes de atuação em saúde (MS, 1994). Nele, o projeto pedagógico é visto como uma construção que possibilita à população o desenvolvimento de estratégias de ação, levando "à superação da dominação $e$ à construção do processo de cidadania”. Esse projeto, conforme o documento mencionado, pressupõe "o entendimento crítico sobre a realidade que se pretende trabalhar" para que se possa colocar "o indivíduo e a doença dentro de um contexto maior de análise, cujo raio de compreensão [abranja] o homem a partir das suas condições de vida, na sua capacidade de organização social e política, nas suas habilidades em utilizar instâncias disponíveis no nível de suas realidades, suas vinculações e relações face ao seu projeto de vida" (MS, 1994:2). Esse documento define participação popular "como um processo onde a população tem o poder de interagir para intervir nas decisões que dizem respeito a sua qualidade de vida, tornando-se sujeito da ação e co-responsável pelo processo de reorganização dos serviços, do controle social, garantindo com isso o exercício da cidadania" (MS, 1994:3).

Na Bahia, a idéia de participação popular ("metodologia participativa") já está presente no Anteprojeto para a Implementação da Metodologia Participativa nos Programas de Controle das Endemias no Estado da Bahia, elaborado em 1988 pela Diretoria Regional da Sucam-BA. Nesse anteprojeto se estabelecem sete objetivos para a "nova metodologia de trabalho junto à comunidade". Entre esses objetivos, propunha-se "vivenciar a prática do 'processo participativo' em áreas pilotos, adquirir conhecimentos que expressem 'a experiência e aspirações das populações em relação aos problemas de saúde", "contribuir para que os indivíduos e grupos 'analisem criticamente' as situações vividas, identifiquem problemas, indiquem prioridades e se organizem para promover as soluções dos mesmos" (Sucam, 1988:2-3, destaques nossos). No documento Programação de atividades para o período de janeiro a dezembro de 1989 (Sucam, 1988), três fatores foram considerados como essenciais para o desenvolvimento da "metodologia participativa": estruturais, organizacionais e pedagógicos. O fator estrutural referia-se à remoção das situações de bloqueios estabelecidas pela própria estrutura 
do órgão administrativo na implementação de novos programas educativos; os fatores organizacionais diziam respeito à reformulação dos aspectos normativos e administrativo que viabilizassem esses programas junto à população; o pedagógico estava relacionado diretamente ao desenvolvimento das ações educativas no controle e prevenção das endemias.

Embora a documentação produzida nos anos 90 pela FNS admita a importância da participação popular e da mobilização comunitária no controle e combate das doenças endêmicas, na prática essas ações se apresentam de forma um tanto problemática. Em primeiro lugar, não existe entre os técnicos e administradores da FNS um consenso sobre qual seria o ideal para a condução das ações pedagógicas. Dentre o conjunto de programas e ações educativas existentes, dois são dominantes e diferem entre si quanto aos objetivos, os sujeitos de ação, os princípios orientadores, estratégias e pressupostos de eficácia. Esse fato pode ser observado até mesmo no interior de uma mesma Diretoria Administrativa. Esses dois conjuntos de idéias são usualmente representados pelos técnicos que trabalham com o componente IEC (Informação, Educação e Comunicação) e a que é posta em prática pelos técnicos do PCTD (Prevenção e Controle da Transmissão da Doença). Para esse último setor, a participação popular e a mobilização devem estar diretamente atreladas às ações malacológicas, aos inquéritos parasitológicos e ao saneamento básico. A educação, nesse caso, é essencialmente pensada como uma estratégia para "conscientizar" a população para o correto uso das instalações sanitárias ou para a devida colaboração com as medidas profiláticas desenvolvidas especificamente para uma determinada endemia. Tal concepção está de certa forma presente, por exemplo, no discurso do inspetor acima citado.

Por outro lado, os técnicos das ações IEC, objetivando gerar transformações nas condutas individuais e coletivas, procuram desenvolver seus objetivos pedagógicos dentro de uma concepção mais abrangente de saúde. Mediante atividades, como cursos, feiras de saúde e, principalmente, organizações associativas, realizadas isoladamente ou em conjunto, os técnicos do IEC tendem a mobilizar a população-alvo (ou segmentos dela) para ações mais globalizantes do que aquelas restritas a determinadas endemias. Nesse aspecto, tais ações tendem a assumir um caráter mais organizacional, reivindicativo e, portanto, político. Como observou um desses técnicos, "o objetivo dos trabalhos nas escolas e das organizações comuni- tárias, por exemplo, é contribuir para que as populações identifiquem conhecimentos, atitudes e práticas prejudiciais à saúde individual e coletiva. Que sejam capazes de participar em grupos, encontrar soluções, adotar novos comportamentos, modificar as situações causadoras de doenças, sejam elas Chagas, esquistossomose, leishmaniose".

É importante observar que essas duas grandes concepções educativas fornecem uma série de explicações e selecionam planos de ação para lidarem com a complexidade da realidade que circunda uma dada população. Algumas vezes, ultrapassam a especificidade das demandas locais das comunidades. Contudo, o que nos interessa salientar é que os programas desenvolvidos pela FNS, em termos gerais, terminam por colocar os seus técnicos (e administradores) em uma posição central no universo sócio-cultural das localidades. Embora nem todos eles tenham a intenção de assumir esse papel, terminam por defrontar ou se confrontar (de formas diferenciadas) com situações e contextos sócio-históricos, político-econômicos, já existentes. A resolução desses encontros dependerá em grande medida da forma em que é conduzido o programa. Não podemos esquecer que a viabilidade e eficácia desses programas em construir de fato uma concepção de saúde dependem da habilidade e flexibilidade dos técnicos (e da instituição) em atuar em um campo de possibilidades de ação encontrado nas localidades. De qualquer forma, qualquer que seja a natureza e condução do programa ou campanha sempre se está a criar na população um substrato sobre o qual os indivíduos elaboram o significado de esquistossomose.

\section{Situações}

As situações apresentadas abaixo - rápidas descrições de localidades - evidenciam algumas formas de atuação no controle e combate da esquistossomose. Constituem exemplos significativos de atividades, combinadas ou não, usualmente desenvolvidas pela Sucam/FNSBA.

\section{Laços}

Localizado próximo a Chapada Diamantina, no município de Tanhaçu (Distrito Administrativo de Jequié), Laços é um povoado de aproximadamente 2000 indivíduos. Essa população vive basicamente do trabalho da roça e da produção de manga. O povoado está assentado em 
terreno alagado por cinco córregos. A água, irrigada por gravidade, é distribuída na superfície por meio de sulcos e pequenas valas. Assim, é virtualmente impossível para a população deixar de mergulhar seus pés nas poças e valas. A grande maioria das 600 casas existentes possui sanitário com uma fossa adjacente. Essas fossas estão próximas às valas - uma distância que raramente ultrapassa 2 metros - situadas nos fundos do quintal. A obra sanitária foi resultado de uma ação da prefeitura, com participação da FSESP, sendo realizada sem maiores preocupações pedagógicas ou informativas.

A taxa de prevalência de esquistossomose é elevadíssima, chegando a mais de $90 \%$. Nesse povoado, além da falta de um trabalho mais sistemático da FNS, não existe um posto de saúde e o médico mais próximo só pode ser encontrado na sede do município (Tanhaçu), uma vez por semana. Mesmo próximo da sede (8 Km), o transporte para esta e outras cidades depende da possibilidade de se conseguir "carona" ou alugar um dos dois carros existentes na localidade. O indivíduo só procura assistência médica quando a doença começa a interferir drasticamente no seu cotidiano. "Antes de começar a sangrar, eu era uma pessoa que não sentia nada, às vezes as pessoas que tem xistosoma dói, eu não sentia dores em momento algum. Xistossomose é uma doença que mata aos pouquinho. Então, algumas pessoas sente aquela dor, que dá uma agulhadazinha. Então ela mata aos pouquinhos, é sugando o sangue, né? (...) Quando me dei conta, já tava doente ..."

Qualquer indivíduo da localidade reconhece que a probabilidade de ser infectado é grande. O xistosoma não é apenas uma designação de um verme: é a doença da comunidade. É interessante observar que toda a população, de uma maneira geral, identifica um conjunto de sintomas relativos à doença. Conforme relato de um morador, "na nossa região, não é tanto o rio, mas os riachos. O rio enche e leva os buzo, mas os riacho (valas de irrigação) não (...) Aqueles buzo é o alojamento deles. Eles aloja ali dentro, quando o sol esquenta ele sai, aí penetra nas pessoas (...) Essa hora os riacho tá cheio de xistosoma (...) Se tiver qualquer cortezinho no pé, ela pega e entra (...) O povo aqui trabalha na água de rega, a gente facilita, trabalha descalço, aí o germe penetra, né. E ataca o bássimo". Há uma quantidade considerável de indivíduos que apresentam formas graves da doença. Nos últimos cinco anos, aproximadamente 50 pessoas sofreram intervenções cirúrgicas. Fizeram “operações de bássimo”, como dizem.

\section{Santiago do Iguape}

Esta localidade (aproximadamente 3000 habitantes) está situada no município de Cachoeira, Recôncavo Baiano (Distrito Administrativo de Pernambués). A pesca é a principal atividade econômica do povoado. Em 1992, a taxa de prevalência de esquistossomose reduziu de $17 \%$ para um nível considerado aceitável, cerca de 3,5\%. Não há registro, por parte da população, de casos graves.

Essa localidade, além de ter sido objeto de constantes ações da FNS e o acesso aos serviços médicos não se constitui em um grande problema, foi "beneficiada” pela FSESP com a instalação de equipamentos sanitários. Contudo, a grande maioria dessas instalações não são atualmente utilizadas, mesmo sendo poucas as casas que possuem sanitário. Esta situação se explica porque a área de Santiago do Iguape, localizada numa região de manguezais, tem um alto índice de umidade e a água é salobra. Assim, mal foram construídas as fossas secas com placas de concreto, a água começou a minar do chão e encher a cavidade. Mosquitos, muriçocas e outros insetos encontraram nesses locais um ambiente propício para o seu desenvolvimento. Conforme disse um morador, "começou a aparecer uma mosca enorme, da bunda azul, que antes não tinha. Veio com o banheiro da SESP". Além disso, segundo as pessoas, o mau cheiro dos sanitários impregnava toda a casa. Logo após construídas, as fossas foram fechadas e os banheiros transformados em depósito, galinheiro, local para jogar lixo, etc. Esses sanitários são chamados pela população local de "banheiro do caramujo".

Durante a instalação dos equipamentos sanitários, houve uma campanha da Sucam para "conscientizar" a população sobre o uso correto dos equipamentos. Esse fator era significativo para que a população local formasse uma concepção da doença. A esquistossomose é vista, antes de mais nada, como um simples nome para designar "um tipo de verme" ("o verme da Sucam") que causa a "barriga d'água”. A população não tem muita informação sobre o ciclo da doença e tampouco faz qualquer distinção entre a esquistossomose e outras verminosas. Para alguns entrevistados, não é do rio, onde pescam, que vem o "verme", mas é a água encanada, em que há alguns resíduos visíveis a olho nu - "umas bolinhas vermelhinhas" - a responsável pela transmissão de doenças. Há, portanto, uma descrença sobre o conteúdo da mensagem transmitido pela FNS. Um informante observou: "Você já viu azulão nascer em ninho de canário? Então como pode a verme vir 
do caramujo? Eu não acredito nisso não. Se fosse assim, em Carcinum (uma localidade próxima), onde a água é cheia dos caramujos, já não existia mais ser vivente e as pessoas tão tudo lá vivinha. É por isso que eu não acho que a verme vem do caramujo, não. A mulher dos banheiros disse isso prá nós, mostrou os caramujo, mas nós não acredita nisso, não”. Um outro relatou: "O caramujo veve dentro do buzo. A verme veve na água, no tempo. Cada um é um tipo de coisa. Como pode um nascer do outro?".

\section{Barragem de Pedra}

Barragem de Pedra (400 habitantes) é um pequeno povoado situado às margens do rio de Contas, município de Jequié. Grande parte da população é composta de trabalhadores rurais ou pequenos proprietários de terra. A proximidade com a sede desse município e, principalmente, as facilidades de transporte minimizam os problemas de acesso aos serviços médicos. Ao longo dos últimos dez anos, tem sido alvo de intensas ações malacológicas, tratamento quimioterápico com a população e ações IEC, constituindo-se como experiência piloto dos educadores da FNS. Essa instituição já utilizou diversas estratégias educativas, como cursos sobre doenças endêmicas, a técnica do "mapa falante”, feiras de saúde, e foi responsável pela criação de uma associação comunitária considerada como paramétrica para a região. Há um forte investimento, tanto por parte dos técnicos quanto da população local, nessa associação.

Atualmente já não existe no povoado uma alta taxa de prevalência e não há nenhum tipo de registro de casos de doença grave provocado pela infecção esquistossomótica. O risco de "pegar xistosa" no rio é reconhecido pelas pessoas, embora não deixem de pescar e utilizar o rio para outras atividades, como o lazer. Nas suas narrativas, os indivíduos sabem que estão infectados após a realização dos exames feitos pelos guardas. Um informante assim definiu: "ela anda, belisca o corpo todo (...) a xistosa renda a pessoa por dentro". Contudo, consideram a esquistossomose como "uma história que as moças da Sucam contam do búzio, que é no búzio que pega a xistosa.".

\section{Cachoeirinha}

Também localizada às margens do rio de Contas, próximo à Barragem de Pedra, Cachoeirinha, povoado por trabalhadores rurais, possui cerca de 700 habitantes. O rio banha o quintal das casas. A taxa de prevalência de esquistos- somose é bastante elevada (acima de 50\%) e a FNS já realizou diversas atividades na localidade (inquéritos parasitológicos e uso de medicamentos esquistossomicidas). A participação dos técnicos do IEC está mais limitada às ações isoladas, voltadas para as campanhas específicas, e eventuais feiras de saúde. A assistência médica é regular. "Pegar xistosa" ou "ter xisto$s a$ " é encarado quase como algo que faz parte da condição normal de vida na localidade. Contudo, as pessoas, apesar de infectadas, não apresentam casos graves da doença. Os que foram infectados só descobriram que estavam com a "doença da verme" após o "trabalho da Sucam”.

A concepção da população local sobre a doença é ambígua, reticente. Por um lado, considera-se que grande parte das sensações de mal estar é devido ao "xistosoma". O caramujo é identificado como a única entidade responsável pela transmissão da doença e o rio é local privilegiado de contágio. Ainda segundo os moradores, evitar o rio seria a principal forma de prevenção da enfermidade. Todavia, por outro lado, a população continua freqüentando o rio. “Ora, se vem gente de Jequié prá tomar banho nesse rio, eu, que sou nascido e criado aqui, não vou tomar meu banho também? O povo não deixa de não tomar". Um outro informante relatou: "Essa doença é um mistério. Repare: o povo diz que pega no rio, a Sucam também diz que é do rio. Mas tem gente que pesca e pega, e já tem outros que pescam e não pegam. É um mistério que eu não sei responder. Eu mesmo nunca tive. Meu menino aí tem. Quer dizer, até agora eu nunca tive. Quando vier o resultado desse exame que fez agora é que eu vou saber se eu tenho dela ou não. Ninguém sabe. Minha mãe passou a vida toda atravessando o rio prá pegar lenha e nunca teve dessa verme. Teve de outra qualidade de verme". E um outro nos disse: "Eu tenho prá mim que ela só entra se você tiver algum cortezinho no pé. Com o pé são, não acho que entre não. Não sei, o pessoal fala muito dessas coisas ... é uma ciência difícil essa xistosoma".

\section{Considerações}

Os casos acima mencionados podem ser, em uma primeira análise, agrupados em duas categorias. A primeira refere-se aos discursos dos informantes encontrados em Laços; a segunda, em Santiago do Iguape, Barragem de Pedra e Cachoeirinha. Em uma segunda análise, podemos observar as diferenças nesse último conjunto de localidades. 
Para entendermos a concepção de esquistossomose em uma localidade como Laços, devemos levar em consideração a existência de altas taxas de prevalência e casos concretos de doença. Os fatores bio-sócio-ecológicos, as dificuldades de acesso aos serviços médicos profissionais e a quase inexistência de campanhas de controle da esquistossomose explicam, entre outros aspectos, a presença de indivíduos que desenvolvem formas agudas ou toxêmicas dessa enfermidade. Assim, a esquistossomose se constitui em experiências concretas, vivenciadas no mundo da vida cotidiana da população. Nessa localidade, a endemia "faz parte" da vida cotidiana das pessoas. O discurso biomédico da doença, embora emitido dentro de um quadro de referência alheio ao sistema cognitivo popular, "faz sentido", pois a mensagem transmitida pelo médico ou agente de saúde pode ser empiricamente testada pela presença de indivíduos portadores de sintomas da doença. Nesse aspecto, a esquistossomose, antes de ser o objeto do qual fala o profissional de saúde, constitui-se uma dimensão da existência da população local.

Em áreas hiperendêmicas, quando grande parte dos seus habitantes adquirem a infecção esquistossomótica, fica claro que a significação dessa enfermidade é socialmente construída tendo como fundamento experiências sensíveis, corporais, tidas como problemáticas. Podemos dizer que a associação entre o significante (sensações) e o seu significado (a doença) traduz uma significação de "primeiro grau". Trata-se, nesse caso, de uma "tomada de consciência” de uma condição sócio-existencial, envolvendo uma percepção corporal. Nesse aspecto, "a enfermidade é subjetivamente dotada de sentido na medida em que é afirmada como real para os membros ordinários da comunidade. É real porque é justamente originada no mundo do senso comum" (Alves, 1993:269).

Os discursos provenientes das outras localidades mencionadas apresentam uma forma diferente. São comunidades em que, tendo ou não elevadas taxas de prevalência, os indivíduos infectados não desenvolvem estados graves da doença. Além do mais, são localidades que foram objetos de campanhas da Sucam, FNS e possuem maiores facilidades de acesso aos serviços médicos. Nelas, a representação popular da esquistossomose não está relacionada a situações concretas de enfermidade. Trata-se de uma doença cuja significação é resultado, em primeira instância, de uma fala, de um discurso cuja matéria foi trabalhada tendo em vista uma comunicação ou ação educativa considerada como apropriada a um determi- nado projeto. Nesse aspecto, a esquistossomose existe porque é assegurada por um discurso biomédico e, mais do que isso, concretizada por programas e campanhas sanitárias.

Não estando presa a uma experiência de sentir-se mal, a uma sensação corpórea ou psíquica de que "algo não vai bem", portanto, a uma percepção direta de um estado corporal tido como problemático, a esquistossomose é, nesse sentido, uma construção ou experiência de "segundo grau". Trata-se de uma experiência cuja significação é essencialmente resultado do testemunho ou discurso de determinados agentes sociais. Nesse aspecto, o significante da doença não está na experiência sensível, no golpe de um objeto imediato, mas em um significante de caráter discursivo. A esquistossomose é afirmada como real para os indivíduos porque é dita como tal por um intérprete ou locutor particular e específico, isso é, pelos agentes e profissionais de saúde. Enquanto experiência de "segundo grau", a esquistossomose é uma fala, um discurso proferido que traz um sentido de apelo e normatividade. A doença é dita mas não percebida.

É necessário entender melhor a natureza e função do discurso formador, instaurador dessa experiência. Uma primeira característica desse discurso é que o objeto da representação (a esquistossomose) é parcialmente subsumido pela forma ou 'maneira' como é proferido esse objeto. Ou seja, a significação da doença (tal como transmitida pelos discursos e ações dos agentes de saúde) é resultado da associação de um modelo teórico (biomédico) de representação do fenômeno patológico com uma determinada imagem realizada desta representação. Trata-se, contudo, de uma associação cuja matéria-prima é constituída, em primeiro lugar, por uma proposta ou intenção de ação informativa, educativa ou pedagógica. Assim, se a "endemia esquistossomótica" é definida inicialmente na sua concepção biomédica, ela é todavia representada e encenada por um locutor que a reflete dentro de parâmetros retirados de um outro campo de significação (educativo ou pedagógico). Há, portanto, uma certa distância que separa a concepção biomédica e a proposta de uma práxis social voltada para o controle da doença. Conseqüentemente, posta a questão de "quem fala", o discurso não se resume apenas a uma objetivação - ao "quê" (sentido) ou a "cerca de quê" do discurso - mas também a uma performance, a uma práxis.

A matéria-prima desse discurso tem um caráter operatório e não apenas temático. Nesse sentido, o discurso do agente de saúde tem a função não apenas de informar mas de em- 
preender ações consideradas como justas e necessárias - um empreendimento que é ao mesmo tempo racionalização, comprometimento, justificativa, apelo e, portanto, criador de uma espaço ideológico. Trata-se, conseqüentemente, de um discurso que traz uma mensagem que nem sempre a crença popular sobre a doença pode acolher ou incorporar.

A significação de uma construção de "segundo grau" nos remete a questões tanto de ordem semiótica quanto hermenêutica. Reduzida em termos semióticos, podemos dizer que essa construção forma uma cadeia de significação particular. Utilizando-se da idéia do "sistema semiológico secundo" do mito, tal como formulado por Barthes (1975), é possível afirmar que a construção de "segundo grau" (assim como o mito) é um signo segundo, um signo cujo significante é já um signo. Ou seja, tratase de uma construção que traduz um processo de conotação, no qual um signo primeiro (associação de um significado e de um significante) se converte por sua vez num significante que, associado a um outro significado, constituirá uma nova unidade, um signo de nível superior. A construção de "segundo grau" tem, portanto, como forma um sentido (ou discurso) prévio.

A idéia de uma cadeia de significação de “segundo grau" está presente tanto na sua emissão, por parte dos agentes de uma política sanitária, quanto na sua recepção, por parte da população-alvo. Pelo lado da emissão, a concepção da endemia é apresentada mediante uma determinada forma, uma leitura, que legitimada em nível político-institucional se apropria do ponto de vista médico para estabelecer um conjunto de ações pautadas em princípios, estratégias e pressupostos de eficácia "educacional”. Desnecessário é lembrar, contudo, que a proposta de um práxis social é sempre proferida em situações e contextos sócio-históricos delimitados e, portanto, filtrada por uma determinada tradição. Conseqüentemente, o discurso sanitário ou educacional é por sua vez recebido, por parte do seu interlocutor (a população-alvo), como um significante no qual estará associado um outro significado, a um horizonte de significados estabelecido pelo mundo da vida cotidiana do interlocutor. Dessa forma, todo discurso emitido pelos educadores ou agentes de saúde é submetido a enquadramentos ou esquemas identificáveis e familiares ao mundo sócio-cultural do interlocutor. Em outras palavras, é por intermédio desses enquadramentos que os indivíduos situam o sentido implícito de uma determinada mensagem.

Cabe observar que em um universo sóciocultural em que a doença está fundamental- mente presa a sintomas percebidos concretamente no corpo, a significação da enfermidade transmitida pelos agentes e profissionais de saúde aparenta ser "descontextualizada”, ambígua e indefinida. Trata-se, nesse caso, de uma mensagem que pode parecer "vazia”. Assim, é de se esperar que a concepção de esquistossomose veiculada pelos programas de controle e combate dessa endemia produza, por parte do seu interlocutor, um campo de possibilidades interpretativas, passíveis de serem violadas ou, na melhor das hipóteses, serem submetidas a uma reinterpretação avessa ao esperado pelo emissor do discurso.

Esse fato pode ser observado, por exemplo, no caráter informativo sobre o ciclo dessa doença. Ao explicar o processo de infecção por S. mansoni, o discurso emitido pelo agente de saúde tende muitas vezes a estabelecer uma idéia de normatividade e apelo associada a uma oposição entre o bem e o mal. O mal é identificado não apenas com o caramujo mas também com o rio. É justamente para os locais em que o abastecimento de água é irregular e onde as opções de lazer são restritas que são dirigidas as mensagens produzidas por um emissor onisciente. Um emissor que em nome de uma doença misteriosa, cheia de segredos profundos, apela para comportamentos normativos singularmente desconfortáveis. Daí é possível compreender determinadas reações, violações por parte do interlocutor. Um informante (Cachoeirinha) sintetizou essa situação ao dizer: "A Sucam diz que pega no rio... mas eu não sei, não (...) tem também uma outra coisa: as pessoas ... as pessoas têm amor ao rio, estão acostumadas com o rio. Eu mesmo sinto falta, não vou mentir. Muita delas (mulheres) têm água em casa, mas quer ir pro rio. A verdade é essa. Ninguém quer ficar sozinha o dia inteiro dentro de casa, podendo se distrair no rio".

Os programas educativos de base preventivista, individualizante, parcial e corretiva (Stotz, 1993) e cuja tônica é "conscientizar" a população para colaborar com as medidas profiláticas planejadas, como usualmente é empregado pelos técnicos do PCTD e alguns setores do IEC, tendem a estabelecer uma relação discursiva do tipo "tribuna" e "platéia”. Nesse tipo de relação a mensagem do locutor está mais distanciada do interlocutor. Os elementos educativos do discurso - âmbito da ação, objetivos, princípios orientadores e estratégias são dirigidos a interlocutores imaginados. Espera-se basicamente que a "platéia" tenha o papel de apreciar as informações feitas e pouco espaço lhe é dado para responder ou indagar. É um discurso que solicita, apela para um 
comportamento adequado sem que se estabeleça necessariamente vínculos mais duradouros com a coletividade e não se compartilha um foco de interesse cognitivo ou de relevância por parte da população. É um discurso que não se pauta em algum conhecimento prévio da cultura local e dos processos que geram significados sociais. Santiago do Iguape (e, em parte, Cachoeirinha) constitui um exemplo ideal desse tipo de enfoque.

Por outro lado, a experiência de "segundo grau" não se constitui necessariamente por cadeias de significação estáticas ou conflitantes. Pode refletir um processo dinâmico e extensivo que se desenvolve e sofre alterações à medida que seus participantes interagem entre si. Quando isso acontece, o processo dialógico emerge com mais nitidez. É nesse processo que a diversidade de discursos pode resultar em uma "fusão de horizontes" ou abertura a novas experiências. Esse é o objetivo final da proposta participativa, da mobilização comunitária que está vinculada a determinados setores de técnicos que trabalham com o componente IEC-PCDEN.

Diferente de Santiago do Iguape, Barragem de Pedra é um caso que exemplifica, em alguns aspectos, o caráter dinâmico entre as duas cadeias de significação mencionadas. Nessa localidade, paralelo às ações medicamentosas típicas da FNS, houve um intenso trabalho dos técnicos do IEC (Distrito Administrativo de Jequié) a fim de se estabelecer um discurso educativo sanitário no qual o combate e controle da esquistossomose estivesse diluído em ações sociais e políticas mais amplas, mais globalizantes do que aquelas restritas a uma determinada endemia. Em certo sentido, pode-se dizer que houve relativo sucesso nesse empreendimento. Diante do desarraigamento da população local com relação às práticas participativas, os técnicos do IEC procuraram estimular um ethos impulsionador de participação mais efetiva no controle e fiscalização da ação governamental. Ancorado em uma complexa interação seletiva entre a FNS, o cotidiano e os valores e crenças tradicionais, o movimento gerado nesse povoado logrou redefinir as relações entre a esfera política e população local, transformando as questões de necessidades e carências em questões de cidadania e de direitos sociais. No processo de interação com os órgãos públicos, as demandas da associação criada na localidade configuraram uma conduta ético-política na reivindicação de direitos, impondo uma identidade gradualmente conquistada frente a uma situação de subalternidade que caracterizava a população. Esse processo, cabe observar, foi desenvolvido mediante certos padrões de convivência com a institucionalidade, sem que existisse uma postura de negação indiscriminada com a esfera político-administrativa local.

Barragem de Pedra, contudo, se constitui como um exemplo um tanto quanto isolado nas ações do IEC. Várias outras experiências produzidas pelos mesmos princípios esbarraram nas contradições de práticas muito distantes entre si em termos de relacionamento entre população, Estado/governo e discurso participativo. Nesses casos, a reprodução de padrões de convivência negativa entre a proposta educativa do IEC e a institucionalidade política autocrática vigente na maior parte das vezes no interior do nosso país resulta na erosão e desativação das redes movimentalistas locais e desarticulação de seu universo cognitivo e simbólico. Esse fato é particularmente significativo tendo em vista a crescente falta de apoio administrativo nos programas organizativo-mobilizadores em "educação popular" por parte da FNS. Assim, o confronto entre uma proposta de mobilização comunitária e os padrões "tradicionais" que norteiam os nossos processos político-administrativos, tende a reduzir as questões de saúde a uma relação custo-benefício. Como resultado desse processo, a concepção de saúde, colocada em termos políticos, gera enquadres múltiplos e variações quanto ao conteúdo do diálogo dentro da gama de opções convencionalmente disponíveis aos participantes. Nesse quadro, como sugere Doimo (1995), há sempre o perigo da reinstauração do amorfismo e da apatia, abrindo-se caminho para a disseminação de interesses privatistas ou de ideologias perversas.

\section{Conclusão}

Assim como a situação de carência e pauperização não leva necessariamente a mobilizações, a alta endemicidade da esquistossomose, por si só, não produz necessariamente uma “consciência da doença”. Por se tratar de uma enfermidade que é na maioria das vezes assintomática, a sua significação não está necessariamente relacionada a experiências concretas, vivenciadas pela população. Assim, a construção social da esquistossomose depende, em larga medida, de uma práxis discursiva promulgada por agentes e profissionais da saúde. Ao dizer algo sobre a doença, esses agentes imersos em uma racionalidade "técnico-científica”, em contextos legitimados por uma instituição - procuram interpretar, descrever ou exprimir o mundo dentro de uma perspectiva 
particular, algumas vezes alheia à situação sócio-cultural da população alvo. Esse aspecto nos parece essencial, pois revela a singularidade ou individualidade de um projeto de transformação social.

Um aspecto importante que deve ser levado em devida consideração para avaliar os programas de controle e combate da esquistossomose diz respeito ao processo pelo qual os indivíduos são "conduzidos” a pensar essa endemia. Sem essa compreensão, um programa pode resultar em fracasso total ou parcial. Esse aspecto torna-se especialmente importante em vista das propostas existentes no programa IEC. Trata-se de ações, como já vimos, orientadas para a implementação de movimentos reivindicatórios que "expressem a experiência e aspirações das populações em relação aos problemas de saúde" (Sucam, 1988:2). Nessa concepção, as ações IEC são vistas como viabilizadoras de uma "cultura política" necessária para que existam de fato as condições mínimas para um processo participativo. Procurando em última instância articular ou fomentar organizações de base, os técnicos do IEC não apenas estabelecem um código ético-político ("uma consciência crítica”) nessas organizações como também, pelas suas ações pedagógicas, sistematizam e possibilitam uma acumulação de conhecimentos sistemáticos sobre o tema saúde necessários na negociação com o Estado. Essa construção, contudo, tem sofrido um processo de gradativa desarticulação no seu campo ético-político. O enfraquecimento desse movimento e a consequente perda de controle sobre o seu próprio destino pode fortalecer as práticas centralizadas e burocratizadas do Estado, uma vez que coloca em risco a possibilidade de se construir um coletivo de interesses e de solidariedade popular nos diferentes e problemáticos momentos de interação com o poder constituído.

\section{Referências}

ALVES, P. C., 1993. A experiência da enfermidade: considerações teóricas. Cadernos de Saúde Pública, 9:263-271

AMMAN, S. B., 1980. Considerações Críticas Sobre Conceitos de Participação. Brasília: Seplantec/ IPEA-Cendec.

BARRETO, M. L., 1984. Esquistossomose Mansônica: Distribuição da Doença e Organização Social do Espaço. Série de Estudos em Saúde, no 6, Salvador: ISEB/CENDRHU

BARTHES, R., 1975. Mitologias. São Paulo: Difel.

BINA, J. C. \& PRATA, A., 1984. A evolução natural da Esquistossomose Mansoni em uma área endêmica. In: Aspectos Peculiares da Infecção por S. mansoni. (Centro de Estudos de Doenças Regionais Cedre, org.), pp. 13-33, Salvador: Centro Editorial da UFBA.

DOIMO, A. M., 1995. A Vez e a Voz do Popular. Rio de Janeiro: Relume-Dumará.

FNS (Fundação Nacional de Saúde). 1995. Diretrizes para o Desenvolvimento de Trabalho Educativo Junto à Comunidade. Jequié: FNS, Coordenadoria Regional da Bahia, Distrito Sanitário de Jequié, Programa de Mobilização Comunitária-Educação em Saúde. (mimeo.)

HUSSERL, E., 1994. Problemas Fundamentales de la Fenomenología. Madrid: Alianza.

IYDA, M., 1994. Cem Anos de Saúde Pública: $a$ Cidadania Negada. São Paulo: Unesp.

KLEINMAN, A., 1980. Patients and Healers in the Context of Culture. Berkeley: University of California Press.

MS (Ministério da Saúde). 1984. Atividades do SesanSuperintendência - Relatório 1984. Brasília: MS/ Sucam, Ditec/Sesan. (mimeo.)
MS (Ministério da Saúde). 1994. Diretrizes de atuação da educação em saúde. Brasília: MS/FNS, Gerência de Educação e Saúde, Comed/Asplan. (mimeo.)

PINTO, J. B. G., 1981. Em Busca do Planejamento Participativo nos PDRIs. Recife: Projeto DRIN-Brasil/ OEA/Sudene.

PRATA, A.; COUTINHO, A; BARBOSA, F. S.; COURA, J. R.; CAETANO, L. \& KATZ, N. 1981. Relatório do grupo de pesquisadores convidados pela Sucam para opinar sobre o Pece. In: Situação e Perspectiva do Controle das Doenças Infecciosas e Parasitárias, (A. Prata, org.), pp. 87-89, Brasília: Editora da Universidade de Brasília.

PRATES, A. A., 1984. A Emergência da Estratégia do Planejamento Participativo no Estado de Minas Gerais: Um Balanço Político-Institucional. Belo Horizonte: Fundação João Pineiro.

REY, L., 1991. Parasitologia. Rio de Janeiro: Guanabara Koogan.

SCHUTZ, A., 1975. On Phenomenology and Social Relations. Selected Writings. Chicago: The University of Chicago Press.

STOTZ, E. N., 1993. Enfoques sobre Educação e Saúde. In: Participação Popular, Educação e Saúde, Teoria e Prática (V. V. Valla \& E. N. Stotz, orgs.), pp.11-22, Rio de Janeiro: Relume-Dumará.

SUCAM (Superintendência de Campanhas de Saúde Pública). 1988. Anteprojeto para a Implantação da Metodologia Participante nos Programas de Controle das Endemias no Estado da Bahia (1988). Salvador: Superintendência de Campanhas de Saúde Pública, Diretoria Regional da Bahia. (mimeo.) 